\title{
Preface
}

\section{Geophysical monitoring of near-surface by electromagnetic and other methods}

\author{
L. V. Eppelbaum ${ }^{1}$ and F. Soldovieri ${ }^{2}$ \\ ${ }^{1}$ Department of Geophysics and Planetary Sciences, Raymond and Beverly Sackler Faculty of Exact Sciences, Tel Aviv \\ University, Tel Aviv 69978, Israel \\ ${ }^{2}$ Istituto per il Rilevamento Elettromagnetico dell'Ambiente, Consiglio Nazionale delle Ricerche, Via Diocleziano 328, \\ 80124 Napoli, Italy
}

This special volume of ADGEO hosts papers that were presented at the session entitled "Geophysical monitoring of near-surface: past, present and future", organized within the framework of the General Assembly of the European Geosciences Union (EGU), held in Vienna, Austria, 1318 April 2008. As the conveners, we invited the contributors to this session to prepare papers reflecting their presentations and submit them for publication in this special volume. Two (and in separated cases three) independent anonymous experts reviewed all the papers involved to this process. Thirteen papers successfully passed through the laborious review process and accepted for publication in this volume.

The papers presented in this volume show the increasing role of electromagnetic and other geophysical methods (gravity, induced polarization, remote sensing, etc.) to achieve information and images of the earth surface and the shallower layers of the underground. In fact, electromagnetic and other geophysical fields monitoring and diagnostics of the shallower near-surface layer $(0-20 \mathrm{~m})$ is of crucial importance for the human activities related to the earth's nearsurface structure.

We hope that the presented research papers will be interesting for readers in the different branches of the Environmental Sciences and will attract new potential contributors to the geophysical monitoring of near-surface.

We wish to thank all the authors for their presentations and fruitful discussions at the session development of the articles. We are grateful to all reviewers, without significant work of which the publication of this volume would not have been possible. We also thank the staff of the Copernicus Publications (first of all - Nadine Diesel and Anna Mirena FeistPolner) for their professional and friendly collaboration. 